\title{
The comparison of the effects of intravenous ketamine or dexmedetomidine infusion on spinal block with bupivacaine
}

\author{
Myoung-Hun Kim, Soon Yong Jung, Jung Dea Shin, Seoung Hun Lee, Min-Young Park, Kun Moo Lee, \\ Jeong Han Lee, Kwangrae Cho, and Wonjin Lee
}

Department of Anesthesiology and Pain Medicine, Busan Paik Hospital, Inje University College of Medicine, Busan, Korea

Background: Ketamine and dexmedetomidine are commonly used for sedation and analgesia in patients. We tried to compare the effects of intravenous ketamine and dexmedetomidine infusion on spinal block with bupivacaine.

Methods: Ninety American Society of Anesthesiologists physical status class I or II patients, who were scheduled to spinal anesthesia were randomly assigned to one of three groups $(\mathrm{n}=30)$. Normal saline $10 \mathrm{ml}, 5 \mathrm{ml} / \mathrm{hr}$ (loading dose for 10 minutes, infusion) (Group NS), dexmedetomidine $1 \mu \mathrm{g} / \mathrm{kg}, 0.5 \mu \mathrm{g} / \mathrm{kg} / \mathrm{hr}$ (Group DEX), or ketamine $0.2 \mathrm{mg} / \mathrm{kg}, 0.5 \mathrm{mg} /$ $\mathrm{kg} / \mathrm{hr}$ (Group KET) was infused intravenously before spinal anesthesia. We recorded the time to highest sensory block level, sensory and motor regression, and hemodynamic changes.

Results: Patients in Groups KET had a significantly faster onset time of sensory block than patients in Group NS. The highest sensory block levels were not significantly different between groups. Average time of sensory regression and knee flexion, was significantly longer in the Group KET and Group DEX than the Group NS.

Conclusions: Intravenous dexmedetomidine and ketamine were found to have a similar synergistic effect with intrathecal bupivacaine. Hemodynamic stability showed better results in Group KET. (Korean J Anesthesiol 2014; 67: 85-89)

Key Words: Dexmedetomidine, Ketamine, Spinal anesthesia.

\section{Introduction}

Spinal anesthesia is widely used because it has many advantages compared to general anesthesia, such as dulling of the stress response, reduced amount of blood loss, low cost, and decreased morbidity and mortality rates in high risk patients [1]. In general anesthesia, it is convenient to administer continuous anesthetic and additional injections of muscle relaxant; however, due to the characteristics of spinal anesthesia in which an additional approach is not easy, various studies have been conducted to extend the duration time. Some methods such as selective a-2 agonist clonidine, local anesthesia, and vasoconstrictors are known to be effective, and it was also shown that dexmedetomidine, a stronger selective $\alpha-2$ agonist than clonidine, has a simi-

Received: April 3, 2013. Revised: 1st, May 26, 2013; 2nd, June 27, 2013. Accepted: July 15, 2013.

Corresponding author: Myoung-Hun Kim, M.D., Department of Anesthesiology and Pain Medicine, Busan Paik Hospital, Inje University College of Medicine, 75, Bokji-ro, Busanjin-gu, Busan 614-735, Korea. Tel: 82-53-890-6520, Fax: 82-51-898-4216, E-mail: pain_kill@naver.com (c) This is an open-access article distributed under the terms of the Creative Commons Attribution Non-Commercial License (http:// creativecommons.org/licenses/by-nc/3.0/), which permits unrestricted non-commercial use, distribution, and reproduction in any medium, provided the original work is properly cited. 
lar effect $[2,3]$. Ketamine, an N-methyl-D-aspartate (NMDA) receptor blocker, also has an anesthetic effect when injected into the intrathecal and a synergic effect with bupivacaine [4]. This study compared the maximum anesthesia level, its onset time, time taken for sensory recovery, time taken for recovery of a certain degree of motor function, and hemodynamic changes when dexmedetomidine and ketamine were IV injected separately during spinal anesthesia using bupivacaine.

\section{Materials and Methods}

This study was conducted with the approval of the Institutional Review Board at our hospital. From the patients scheduled for surgery with spinal anesthesia, 90 patients with American Society of Anesthesiologists (ASA) physical status class 1 or 2 , with an age of 20 or over but less than 65 , were chosen as subjects. At the preoperational visit, the purpose of the research was explained to obtain consent. Patients with heart or lung disease, patients taking antihypertensive drugs, patients with kidney or liver disease, patients who had taken central nervous system drugs, and patients with endocrine diseases or nerve diseases in their past medical history were excluded from the study.

There was no premedication and after arriving in the operating room, vital signs were monitored with electrocardiogram, non-invasive blood pressure, and $\mathrm{SpO}_{2}$. Thirty patients were randomly divided into 3 groups: the control group was administered normal saline (Group NS) and another group was administered dexmedetomidine (Group DEX) while the other group ketamine (Group KET). Blood pressure and heart rate were measured in the supine position and then the patient was immediately put in the right lateral position. From here, the loading dose according to each group was administered for 10 minutes, and spinal anesthesia was completed while the loading dose was being administered. Then, the patient was put in the supine position again, and continuous infusion was started after completing the administration of the loading dose. Spinal anesthesia was performed by injecting $10 \mathrm{mg}$ of $0.5 \%$ hyperbaric bupivacaine with a $25 \mathrm{G}$ Whitacre needle (Becton-Dickinson, Franklin Lakes, NJ) between L4-5. After the patient was put in the supine position, a pin-prick test was performed every 2 minutes to record the time and level of highest sensory block, and

Table 1. Modified Bromage Score (Intensity of Motor Block)

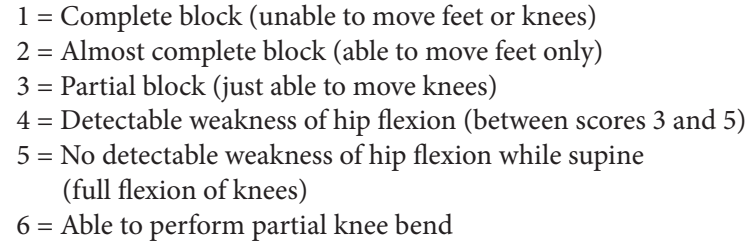

1 hour after spinal anesthesia, the pin-prick test was performed every 10 minutes to record the time taken for sensory regression of the two dermatomes. For recovery of the motor nerves, the motor regression time at a Bromage score of 4 modified by Breen et al. [5] was recorded (Table 1). Group NS was administered $10 \mathrm{ml}$ of normal saline for 10 minutes, and then received a continuous infusion at $5 \mathrm{ml} / \mathrm{hr}$. Group DEX was administered $\mathrm{h}$ $1 \mu \mathrm{g} / \mathrm{kg}$ for 10 minutes, and then received a continuous infusion at $0.6 \mu \mathrm{g} / \mathrm{kg} / \mathrm{hr}$. Group KET was administered $0.2 \mathrm{mg} / \mathrm{kg}$ for 10 minutes, and then received a continuous infusion at $0.5 \mathrm{mg} / \mathrm{kg} / \mathrm{hr}$.

Statistical analysis was done with the SPSS program (version 18.0, SPSS Incorporation, Chicago, IL, USA). Regarding each group, repeated measures ANOVA was done for comparison within a group; one way ANOVA was done for comparison between groups, and Tukey's test was done for the posthoc test. A result was considered to be statistically significant when the $\mathrm{P}$ value was less than 0.05 .

\section{Results}

There were no statistically significant differences observed in sex, age, height, weight, ASA class, and operation time between the groups (Table 2).

When the difference in hemodynamic changes was examined, there was no statistically significant difference between the 3 groups. However, Group DEX showed a decreasing tendency for heart rate over time. When compared to baseline $(79.0 \pm$ 14.4 beats/min), the heart rate at 10 minutes $(71.7 \pm 11.5$ beats/ min), 20 minutes $(62.7 \pm 10.6$ beats $/ \mathrm{min}), 30$ minutes $(59.3 \pm 9.1$ beats/min), 40 minutes ( $60.0 \pm 7.2$ beats $/ \mathrm{min}), 50$ minutes $(59.9$ \pm 6.9 beats $/ \mathrm{min}$ ), and 60 minutes $(59.3 \pm 7.2$ beats $/ \mathrm{min}$ ) were all significantly lower. Even when compared to the heart rate of the same group at 10 minutes, the heart rate at 20 minutes, 30 minutes, 40 minutes, 50 minutes, and 60 minutes were also significantly lower. In addition, comparing between groups, there was no significant difference in heart rate between Group NS and the other groups; however, between Group DEX and Group KET, the heart rate of Group DEX was significantly lower than that of

Table 2. Demographic Data

\begin{tabular}{lccc}
\hline & $\begin{array}{c}\text { Group NS } \\
(\mathrm{n}=30)\end{array}$ & $\begin{array}{c}\text { Group DEX } \\
(\mathrm{n}=30)\end{array}$ & $\begin{array}{c}\text { Group KET } \\
(\mathrm{n}=30)\end{array}$ \\
\hline Age $(\mathrm{yr})$ & $46.9 \pm 16.0$ & $48.9 \pm 15.3$ & $47.3 \pm 14.7$ \\
Height $(\mathrm{cm})$ & $166.6 \pm 10.7$ & $164.9 \pm 10.6$ & $165.4 \pm 11.6$ \\
Weight $(\mathrm{kg})$ & $64.8 \pm 11.4$ & $63.6 \pm 10.8$ & $62.9 \pm 8.1$ \\
Gender $(\mathrm{M} / \mathrm{F})$ & $16 / 14$ & $13 / 17$ & $14 / 16$ \\
ASA class $(\mathrm{I} / \mathrm{II})$ & $22 / 8$ & $23 / 7$ & $22 / 8$ \\
Time of surgery (min) & $54.5 \pm 9.8$ & $52.4 \pm 8.9$ & $57.0 \pm 9.5$ \\
\hline
\end{tabular}

Values are expressed as mean \pm SD or number of patients. NS: Normal saline, DEX: Dexmedetomidine, KET: Ketamine. N: number of patients. 
Group KET at 20 minutes $(71.0 \pm 10.2$ vs $62.7 \pm 10.6$ beats $/ \mathrm{min})$, 30 minutes $(69.9 \pm 9.7$ vs $59.3 \pm 9.1$ beats $/ \mathrm{min}), 40$ minutes $(70.1$ \pm 9.6 vs $60.0 \pm 7.2$ beats $/ \mathrm{min}), 50$ minutes $(68.8 \pm 8.4$ vs $59.9 \pm 6.9$ beats/min) and 60 minutes $(67.8 \pm 9.8$ vs $59.3 \pm 7.2$ beats $/ \mathrm{min})$ (Fig. 1).

There were no significant differences in mean blood pressure for all 3 groups when compared according to time. When comparing within groups, Group NS and Group KET did not show any change according to time; however, in Group DEX, the baseline blood pressure was significantly higher than the blood pressure at 40,50, and 60 minutes, and the blood pressure at 10 minutes was also significantly higher than the blood pressure at 60 minutes (Table 3). The results of the pin-prick test to check the level of the sensory block from the spinal anesthesia showed that the highest sensory block level was equally around the T6 dermatome (Table 4). However, there was a slight difference in the onset time to reach the highest level where Group NS appeared to have a significantly longer onset time than that of Group KET. The time taken for sensory regression of the two dermatomes and motor regression showed that Group NS appeared to recover significantly faster than that of Group KET and Group DEX (Table 4).

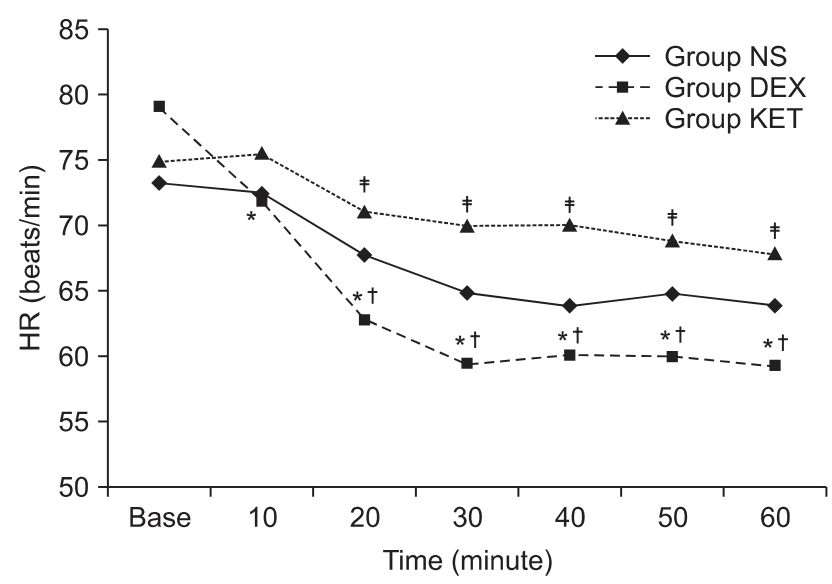

Fig. 1. Change of heart rate (HR). $* \mathrm{P}<0.05$ compared to baseline HR within Group DEX. ${ }^{\dagger} \mathrm{P}<0.05$ compared to $10 \mathrm{~min}$ HR Group DEX. ${ }^{\ddagger} \mathrm{P}<0.05$ compared to Group DEX. NS: Normal saline, DEX: Dexmedetomidine, KET: Ketamine.

\section{Discussion}

Ketamine was first developed in 1962 to be used widely as an anesthetic, sedative, analgesic, and bronchodilator, and it has been used especially for its analgesic effect, maintaining a normal pharyngeal reflex, and used in patients who need sedation because the respiratory depression effect is less [6,7]. Drawbacks are tachycardia and hypertension from the secretion of catecholamine, increased skeletal muscle tone, increased cerebrospinal fluid pressure, and a possibility of delirium and nightmares during recovery $[5,6]$. These drawbacks usually happen when 1 $\mathrm{mg} / \mathrm{kg}$ or more is administered; thus, there have been studies on the administration of low doses of ketamine to reduce such drawbacks. Cagla et al. [8] reported that the administration of a low dose of ketamine $(0.15 \mathrm{mg} / \mathrm{kg})$ in arthroscopic knee surgery was effective in reducing postoperative pain. Sen et al. [9] also reported that in caesarean section using local anesthesia, administration of a low dose of ketamine $(0.15 \mathrm{mg} / \mathrm{kg})$ was more effective in reducing postoperative pain than that of intrathecal administration of fentanyl $10 \mu \mathrm{g}$ together with bupivacaine. In the above studies, there were no reports of complications caused by ketamine.

Dexmedetomidine is a strong $\alpha-2$ agonist, and since approved by the FDA in 1999, its use has gradually increased not only for the sedation of critical patients, but for the sedation and reduction of the stress response in the operating room. Kara et al. [10]

Table 3. Mean Blood Pressure Data

\begin{tabular}{lccc}
\hline & $\begin{array}{c}\text { Group NS } \\
(\mathrm{n}=30)\end{array}$ & $\begin{array}{c}\text { Group DEX } \\
(\mathrm{n}=30)\end{array}$ & $\begin{array}{c}\text { Group KET } \\
(\mathrm{n}=30)\end{array}$ \\
\hline Base MBP & $90.4 \pm 11.1$ & $95.1 \pm 11.5$ & $94.0 \pm 11.5$ \\
$10 \mathrm{~min}$ MBP & $84.6 \pm 11.7$ & $92.9 \pm 10.4$ & $92.0 \pm 9.2$ \\
$20 \mathrm{~min}$ MBP & $82.4 \pm 12.5$ & $86.7 \pm 10.8$ & $87.8 \pm 10.4$ \\
$30 \mathrm{~min}$ MBP & $81.9 \pm 12.5$ & $84.7 \pm 12.5$ & $88.5 \pm 11.4$ \\
$40 \mathrm{~min}$ MBP & $80.8 \pm 12.1$ & $83.5 \pm 12.6^{*}$ & $87.6 \pm 11.2$ \\
$50 \mathrm{~min}$ MBP & $82.6 \pm 10.8$ & $82.6 \pm 13.8^{*}$ & $86.4 \pm 13.4$ \\
$60 \mathrm{~min}$ MBP & $83.7 \pm 11.6$ & $80.5 \pm 14.0^{*,+}$ & $86.4 \pm 12.5$ \\
\hline
\end{tabular}

Values are expressed as mean \pm SD. $* \mathrm{P}<0.05$ compared to base MBP within Group DEX. ${ }^{\dagger} \mathrm{P}<0.05$ compared to 10 min MBP within Group DEX. MBP: Mean blood pressure (mmhg), NS: Normal saline, DEX: Dexmedetomidine, KET: Ketamine.

Table 4. Block Regression Times in Minutes and Block Level

\begin{tabular}{lccc}
\hline & Group NS & Group DEX & Group KET \\
\hline Onset time of highest sensory block level (min) & $13.2 \pm 1.8$ & $11.8 \pm 2.0$ & $11.1 \pm 2.5^{*}$ \\
Highest sensory block level of dermatome (thoracic level) & $6.8 \pm 1.2$ & $6.1 \pm 1.4$ & $6.2 \pm 1.5$ \\
Sensory regression of two dermatomes (min) & $99.2 \pm 10.8^{\dagger}$ & $121.6 \pm 13.9$ & $117.5 \pm 13.9$ \\
Motor regression time at modified bromage score 4 (min) & $123.7 \pm 18.9^{\dagger}$ & $144.8 \pm 21.7$ & $138.1 \pm 22.1$ \\
\hline
\end{tabular}

Values are expressed as mean $\pm \mathrm{SD} .{ }^{*} \mathrm{P}<0.05$ compared to Group NS, ${ }^{\dagger} \mathrm{P}<0.05$ compared to Group DEX and Group KET. NS: Normal saline, DEX: Dexmedetomidine, KET: Ketamine. 
reported that a single administration of dexmedetomidine 0.5 $\mu \mathrm{g} / \mathrm{kg}$ in local anesthesia increased the highest anesthesia level and time taken for sensory regression of the two dermatomes after anesthesia. There are also reports that dexmedetomidine was effective in reducing postoperative pain $[11,12]$.

In our experiment, there was no occurrence of complications caused by ketamine such as delirium, tachycardia, hypertension, or dizziness. Severe hypotension or bradycardia of 50 beats/min or less caused by dexmedetomidine also did not appear. However, blood pressure and heart rate continuously decreased when dexmedetomidine was administered, so it is considered necessary to monitor patients administered dexmedetomidine more carefully.

In most studies that examined the effect of ketamine or dexmedetomidine in spinal anesthesia, the medication was usually infused after the administration of bupivacaine. In our study, continuous infusion of a low dose of ketamine and dexmedetomidine was started before the administration of bupivacaine, so it is thought that the administered medication had a stronger effect on the bupivacaine compared to the other studies. As a result, there was no difference in maximum anesthesia level between the three groups; however, compared to Group NS, the time taken for sensory regression of the two dermatomes and until bending of the knees was significantly extended in Group KET and Group DEX. There was no significant difference when comparing Group KET and Group DEX. The mechanism of ketamine and dexmedetomidine is different, but both showed a similar degree of synergic effect for intrathecal bupivacaine. Regarding the infusion of the drugs before the administration of bupivacaine, there seems to be no large difference compared to the research of Al-Mustafa et al. [13] ; however, their administered dose of bupivacaine was different from ours so an accurate comparison is difficult. The mechanism for extending the time of the spinal anesthesia has not been clearly elucidated yet, but dexmedetomidine affects the locus ceruleus of the brain stem, and the locus ceruleus is connected to the noradrenergic nuclei. The axon terminal of the noradrenergic nuclei reaches the ventral horn of the spinal cord. Hence, it is known that the strong $\alpha-2$ agonist causes the inhibition of the locus ceruleus and disinhibition of the noradrenergic nuclei, to strengthen the descending inhibitory effect in the spinal cord. It is assumed that the synergic effect with intrathecal bupivacaine appears due to such an effect [13]. Ketamine is also known to combine with NMDA receptors in the spinal cord to inhibit its functions and affect the voltage-sensitive calcium channels with opiate and with monoaminergic receptors to cause analgesic and anesthetic effects [14]. Hence, ketamine is also considered to show a synergic effect with intrathecal bupivacaine for the above reasons. For the change in heart rate and blood pressure, all three groups showed a decreasing tendency for the first 20 minutes, but Group KET and Group NS stabilized after 20 minutes while Group DEX showed a continual decline with the largest variation in change. In conclusion, the administration of a low dose of ketamine and dexmedetomidine in local anesthesia showed a synergic effect with intrathecal bupivacaine, and it is considered that there will be a better effect on reducing postoperative pain. Therefore, when performing local anesthesia for a long period of time, it is effective to infuse dexmedetomidine for sleep induction, while in short-term local anesthesia, administration of a low dose of ketamine is better because it is more stable in terms of hemodynamic aspects. However in this study, there was no difference in the maximum anesthetic level compared to the control group, but there was an observation of an increase in Group KET and Group DEX (Table 4). In an experiment where bupivacaine $15 \mathrm{mg}$ was administered, the maximum anesthesia level was significantly higher when dexmedetomidine was infused; therefore, it is thought that the synergic effect is strengthened in proportion to the dosage of bupivacaine [10]. Thus, when administering ketamine or dexmedetomidine in local anesthesia, it should be done keeping in mind that the anesthesia level can increase. Finally, although it was not compared in this research, many studies have stated that the infusion of ketamine and dexmedetomidine has a positive effect in reducing postoperative pain. Therefore, comparing the degree of reduced postoperative pain for the two drugs will be a good area to research. It will also be interesting to investigate whether there is a synergic effect when ketamine and dexmedetomidine are administered simultaneously in local anesthesia. In conclusion, it was found that dexmedetomidine and ketamine were effective in extending the time duration of intrathecal bupivacaine $10 \mathrm{mg}$ for a similar length of time.

\section{Acknowledgments}

This work supported by the 2012 Inje University Research Grant.

\section{References}

1. Gaiser RR. Spinal, Epidural, and Caudal Anesthesia. In: Introduction to anesthesia. 9th ed. Philadelphia, W. B. Saunders Company. 1997, pp 230-1.

2. Rhee KY. Intravenous clonidine prolongs spinal anesthesia after hyperbaric bupivacaine. Korean J Anesthesiol 2003; 44: 354-8. 
3. Kanazi GE, Aouad MT, Jabbour-Khoury SI, Al Jazzar MD, Alameddine MM, Al-Yaman R, et al. Effect of low-dose dexmedetomidine or clonidine on the characteristics of bupivacaine spinal block. Acta Anaesthesiol Scand 2006; 50: 222-7.

4. Togal T, Demirbilek S, Koroglu A, Yapici E, Ersoy O. Effects of S(+) ketamine added to bupivacaine for spinal anaesthesia for prostate surgery in elderly patients. Eur J Anaesthesiol 2004; 21: 193-7.

5. Breen TW, Shapiro T, Glass B, Foster-Payne D, Oriol NE. Epidural anesthesia for labor in an ambulatory patient. Anesth Analg 1993; 77: 919-24.

6. Stevenson C. Ketamine: A review. Update in Anaesthesia 2005; 20: 25-9.

7. Craven R. Ketamine. Anaesthesia 2007; 62 Suppl 1: 48-53.

8. Cagla Ozbakis Akkurt B, Inanoglu K, Kalaci A, Turhanoglu S, Asfuroglu Z, Tumkaya F. Effects of intravenous small dose ketamine and midazolam on postoperative pain following knee arthroscopy. Pain Pract 2009; 9: 289-95.

9. Sen S, Ozmert G, Aydin ON, Baran N, Caliskan E. The persisting analgesic effect of low-dose intravenous ketamine after spinal anaesthesia for caesarean section. Eur J Anaesthesiol 2005; 22: 518-23.

10. Kaya FN, Yavascaoglu B, Turker G, Yildirim A, Gurbet A, Mogol EB, et al. Intravenous dexmedetomidine, but not midazolam, prolongs bupivacaine spinal anesthesia. Can J Anaesth 2010; 57: 39-45.

11. Park JK, Cheong SH, Lee KM, Lim SH, Lee JH, Cho K, et al. Does dexmedetomidine reduce postoperative pain after laparoscopic cholecystectomy with multimodal analgesia? Korean J Anesthesiol 2012; 63: 436-40.

12. Gurbet A, Basagan-Mogol E, Turker G, Ugun F, Kaya FN, Ozcan B. Intraoperative infusion of dexmedetomidine reduces perioperative analgesic requirements. Can J Anaesth 2006; 53: 646-52.

13. Al-Mustafa MM, Badran IZ, Abu-Ali HM, Al-Barazangi BA, Massad IM, Al-Ghanem SM. Intravenous dexmedetomidine prolongs bupivacaine spinal analgesia. Middle East J Anesthesiol 2009; 20: 225-31.

14. Kathirvel S, Sadhasivam S, Saxena A, Kannan TR, Ganjoo P. Effects of intrathecal ketamine added to bupivacaine for spinal anaesthesia. Anaesthesia 2000; 55: 899-904 